\title{
Desenvolvimento e Caracterização de Suportes Porosos de Polietileno de Ultra Alto Peso Molecular (PEUAPM) para Utilização como Biomaterial para Reposição e Regeneração Óssea
}

\author{
Anahi H. Aparecida, Antonio C. Guastaldi \\ Instituto de Química, UNESP \\ Marcus V. L. Fook \\ Departamento de Engenharia de Materiais, UFCG
}

\begin{abstract}
Resumo: O uso de polímeros como biomateriais tem crescido nos últimos anos, principalmente como suportes poliméricos para regeneração tridimensional e substituição de tecidos. Embora o polietileno de ultra alto peso molecular (PEUAPM) apresente vantagens na sua utilização como biomaterial, principalmente como implante ortopédico, sua baixa reatividade química constitui-se como fator limitante para sua interação com o tecido ósseo. Neste contexto, a modificação morfológica deste polímero, tornando-o um material poroso, e sua associação com um material bioativo pode proporcionar a obtenção de um biomaterial adequado para a regeneração e reposição do tecido ósseo. Neste trabalho, foram preparados e caracterizados suportes porosos de PEUAPM, pela combinação das técnicas de lixiviação de sal e moldagem por compressão com a aplicação de diferentes pressões de compactação, visando a sua utilização como biomaterial para reposição e regeneração óssea. Os suportes poliméricos apresentaram porosidade interconectada com diâmetro médio de poros entre 34 e $49 \mu \mathrm{m}$ e porosidade entre 39 e 53\%, podendo ser classificados adequados para a utilização como biomaterial poroso.
\end{abstract}

Palavras-chave: Biomateriais, polietileno de ultra alto peso molecular (PEUAPM), biomateriais porosos, lixiviação de sal, moldagem por compressão.

\section{Development of Ultra High Molecular Weight Polyethylene (UHMWPE) Porous Supports for Use as Biomaterial in Osseous Replacement and Regeneration}

Abstract: The use of polymer as biomaterials has increased in recent years, mainly as polymeric supports in the threedimensional regeneration and substitution of tissues. Although the ultra high molecular weight polyethylene (UHMWPE) shows advantages in its use as biomaterial, particularly as orthopedic implants, its low chemical reactivity constitutes a limiting factor for interaction with the osseous tissue. The morphological modification of this polymer, leading to a porous material, and its association with a bioactive material can provide tailored biomaterials for the regeneration and replacement of osseous tissue. In this work, polymeric porous supports have been prepared by combining the techniques of salt leaching and compression molding with the application of distinct compression pressures. The polymeric supports showed interconnected porosity with size of pores between 34 and $49 \mu \mathrm{m}$ and porosity between 39 and 53\%, which can then be considered as suitable porous biomaterial.

Keywords: Biomaterials, ultra high molecular weight polyethylene (UHMWPE), porous biomaterials, salt leaching, compression molding.

\section{Introdução}

Os biomateriais podem ser considerados como produtos aptos para serem utilizados nos seres humanos com a finalidade de tratamento ou alívio de uma enfermidade ou lesão, e também para a substituição e modificação de sua anatomia ou de um processo fisiológico. Por isso, incluem qualquer produto natural, sintético e natural modificado que pode ser utilizado como um dispositivo médico ou parte dele. Os materiais sintéticos utilizados para este fim incluem metais, polímeros e cerâmicas e também a combinação destes nos chamados compósitos ${ }^{[1,2]}$.

Grande atenção tem sido dada ao desenvolvimento de biomateriais porosos, incluindo a produção de membranas, recobrimentos e implantes ${ }^{[3]}$. A presença de poros na superfície de implantes proporciona sua fixação com o tecido vivo por crescimento de tecido através dos poros por todo o implante. Esta ligação tecido/implante poroso é denomina-

Autor para correspondência: Anahi H. Aparecida, Laboratório de Biomateriais, Departamento de Físico-Química, Instituto de Química, Universidade Estadual Paulista (UNESP), CEP: 14800-900, Araraquara, SP, Brasil. E-mail: aherrera@iq.unesp.br 
da fixação biológica e é capaz de suportar estados complexos de carga ${ }^{[4,5]}$. Em engenharia de tecidos, a utilização de suportes porosos denominados scaffolds tem como objetivo a reconstrução de novos órgãos e tecidos ${ }^{[5,6]}$.

O tamanho e a interconectividade dos poros, bem como permeabilidade e química da superfície dos biomateriais têm crucial influência na formação óssea. Um tamanho mínimo de poro entre 100 e $150 \mu \mathrm{m}$ foi inicialmente estabelecida como o critério mais importante para um crescimento continuado do osso no interior dos poros, devido ao tamanho das células, necessidades de migração e transporte, mas isso ainda é controverso $^{[7,8]}$. Klawitter et al. e Simslke et al. estabeleceram um tamanho mínimo de poros de aproximadamente $100 \mu \mathrm{m}$ para o crescimento ósseo dentro da estruturas porosas de cerâmicas, com a presença de poros interconectados para permitir o crescimento interno das células, a vascularização e a difusão de nutrientes ${ }^{[9]}$. Apresenta-se aceita uma interconectividade mínima de $100 \mu \mathrm{m}$ para o crescimento interno do tecido mineralizado, porém Ítala et al. ${ }^{[10]}$ mostraram um bom crescimento ósseo dentro de poros com tamanhos de 50 a $125 \mu \mathrm{m}$.

Os polímeros apresentam grande potencial de utilização biomédica, pois são, geralmente, fáceis de produzir e manusear e apresentam propriedades mecânicas semelhantes às dos materiais biológicos ${ }^{[11,12]}$. Biopolímeros porosos têm sido usados em várias aplicações biomédicas devido às suas vantagens em relação aos biopolímeros densos, tais como: baixa densidade, maior eficiência na fixação com o tecido vivo e elevada processabilidade. Em engenharia de tecidos, biopolímeros reabsorvíveis e bioinertes são utilizados como scaffold, contudo a utilização de biopolímeros bioinertes somente é adequada com a sua associação com um material bioativo. Os materiais bioativos mais utilizados e de bioatividade satisfatória são as cerâmicas de fosfato de cálcio, denominadas apatitas.

Vários tipos de processamento possibilitam a obtenção de biopolímeros porosos, dos quais podem se destacar ${ }^{[12,13]}$ : lixiviação de partículas solúveis, freeze-drying, utilização de agente expansor e impressão tridimensional. Alguns trabalhos mostram que a combinação de lixiviação de partículas de sal com moldagem a alta temperatura mostrou-se eficiente na obtenção de superfícies altamente porosas, tendo sido muito empregada atualmente ${ }^{[13]}$. A Tabela 1 compara os métodos de obtenção de polímeros porosos.

As propriedades do polietileno de ultra alto peso molecular (PEUAPM) tornam este material um dos polímeros mais utilizados como biomaterial, principalmente em próteses de joelho e de quadril, contudo propiciam duas situações anta- gônicas: o baixo coeficiente de fricção e a reduzida perda de volume por abrasão constituem-se em características desejáveis deste material, porém, sua baixa reatividade química, decorrente da apolaridade da cadeia polimérica, apresenta-se como desvantagem quando este material entra em contato com osso, impossibilitando sua fixação com este tecido. Neste contexto, a modificação morfológica do polímero, tornando-o um material poroso, e a sua associação com um material bioativo proporcionaria a obtenção de um biomaterial adequado para a regeneração e reposição do tecido ósseo ${ }^{[14-17]}$.

Os objetivos deste trabalho foram a obtenção e caracterização de suportes porosos de PEUAPM, a partir da combinação das técnicas de lixiviação de partículas de sal e moldagem por compressão, visando sua utilização como biomaterial poroso para reposição e regeneração óssea.

\section{Material e Métodos}

Suportes porosos de PEUAPM foram obtidos utilizando-se $\mathrm{NaCl}$ como agente porogênico na proporção de $20 \%$ em massa. O tamanho das partículas do sal foi controlado na faixa granulométrica de 50 a $175 \mu \mathrm{m}$. Os componentes em pó (PEUAPM do tipo UTEC 6541 e $\mathrm{NaCl}$ de grau analítico) foram misturados em almofariz e então moldados por compressão utilizando-se prensa uniaxial, aplicando-se pressões de 0,$5 ; 1,0 ; 1,5 ; 2,0 ; 2,5$ e 3,0 toneladas. Após moldadas, as amostras foram submetidas a tratamento térmico a $165^{\circ} \mathrm{C}$ por 2 horas, com taxa de aquecimento e resfriamento de $5{ }^{\circ} \mathrm{C} / \mathrm{min}$, e então lavadas em água destilada quente para promover a lixiviação das partículas de $\mathrm{NaCl}$. Foram obtidos 3 suportes porosos com $1,2 \mathrm{~cm}$ de diâmetro e $0,5 \mathrm{~cm}$ de altura para cada condição de pressão.

Os suportes porosos obtidos foram analisados pelas técnicas de microscopia eletrônica de varredura (MEV) e porosimetria por intrusão de mercúrio.

\section{Resultados e Discussão}

A utilização de larga faixa granulométrica das partículas do agente porogênico associada à aplicação de diferentes pressões de compactação permitiu a obtenção de amostras poliméricas porosas com diferentes tamanhos de poros e elevada porosidade, com a presença de poros interconectados e também isolados, Figura 1.

Os diâmetros médios de poros variaram de 39 a $49 \mu \mathrm{m}$ e a maioria das amostras apresentou porosidade superior a $50 \%$, Tabela 2. A baixa porosidade exibida pela amostra ob-

Tabela 1. Comparação dos métodos de obtenção de polímeros porosos.

\begin{tabular}{cccc}
\hline Método & $\begin{array}{c}\text { Diâmetro de } \\
\text { poros }(\mu \mathbf{m})\end{array}$ & Porosidade (\%) & Características \\
\hline Lixiviação de partículas de sal & $30-300$ & $20-60$ & Poros esféricos interconectados \\
Freeze-drying & $<200$ & $<97$ & Macroporos interconectados e microporosidade presente \\
Utilização de agente expansor & $20-500$ & $<60$ & Poros não totalmente interconectados \\
Impressão tridimensional & $45-100$ & $<60$ & Poros totalmente interconectados \\
\hline
\end{tabular}




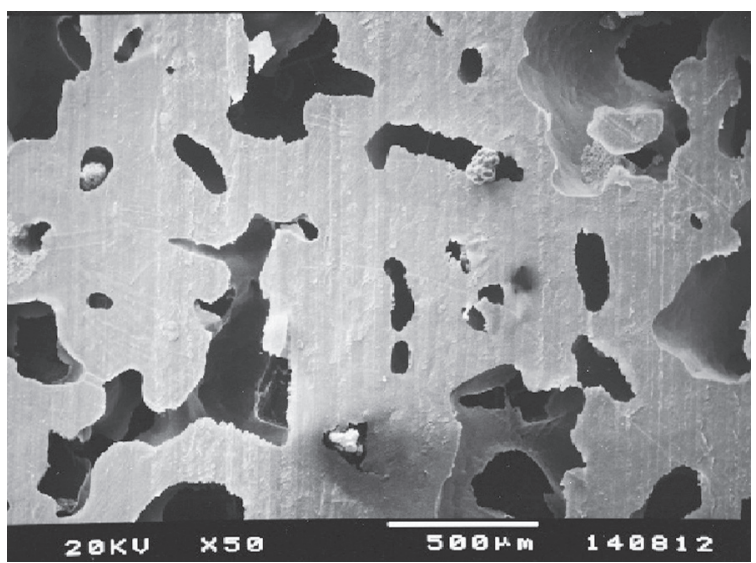

(a)

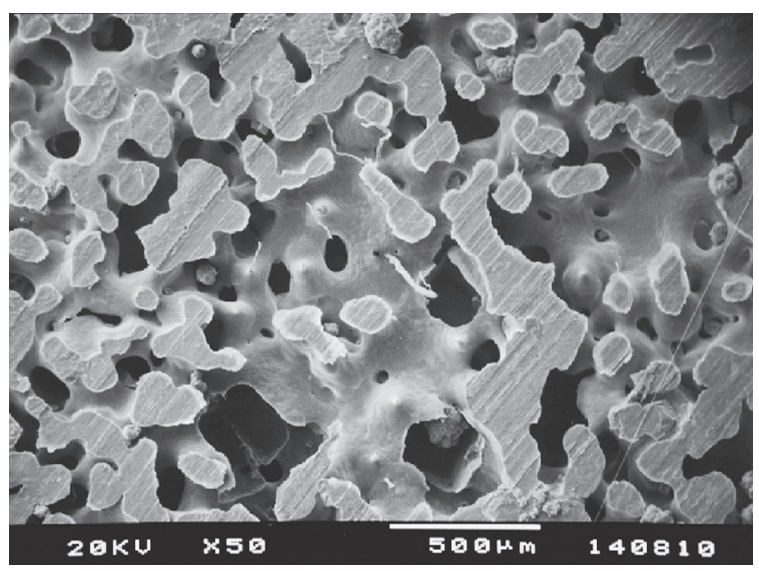

(b)

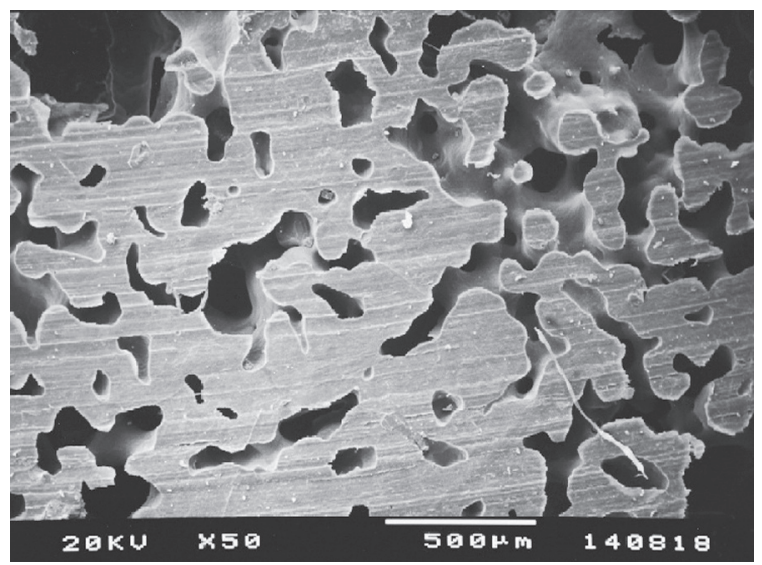

(c)

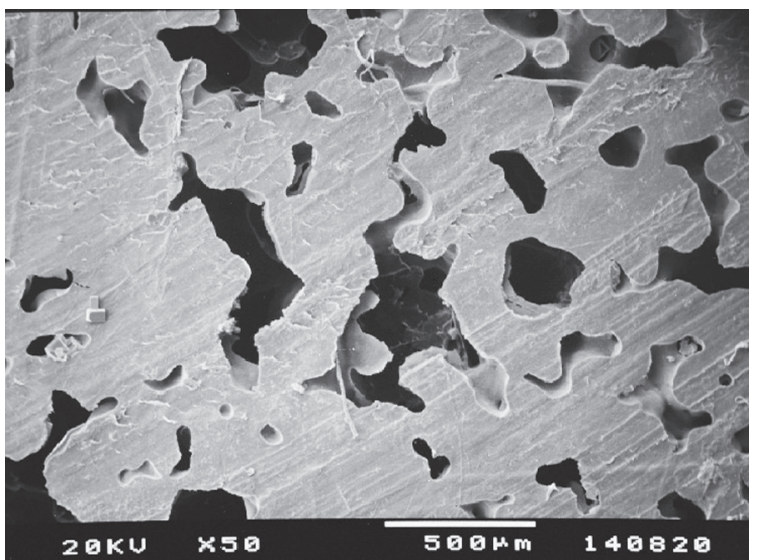

(d)

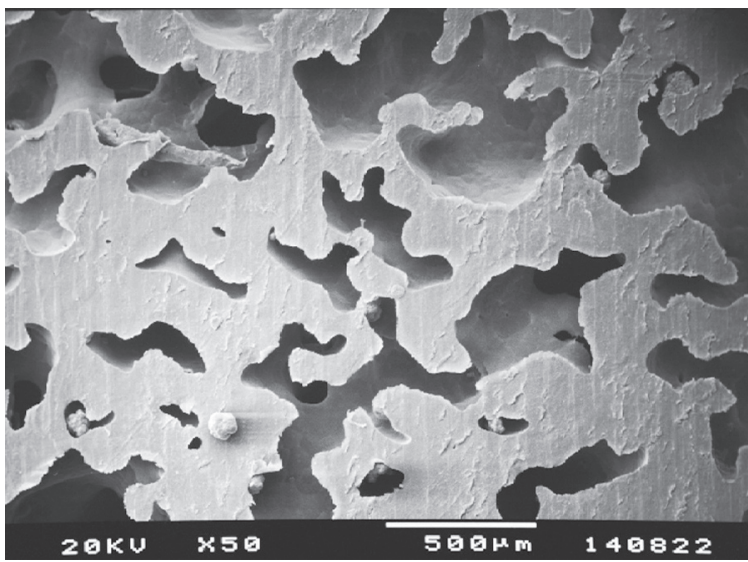

(e)

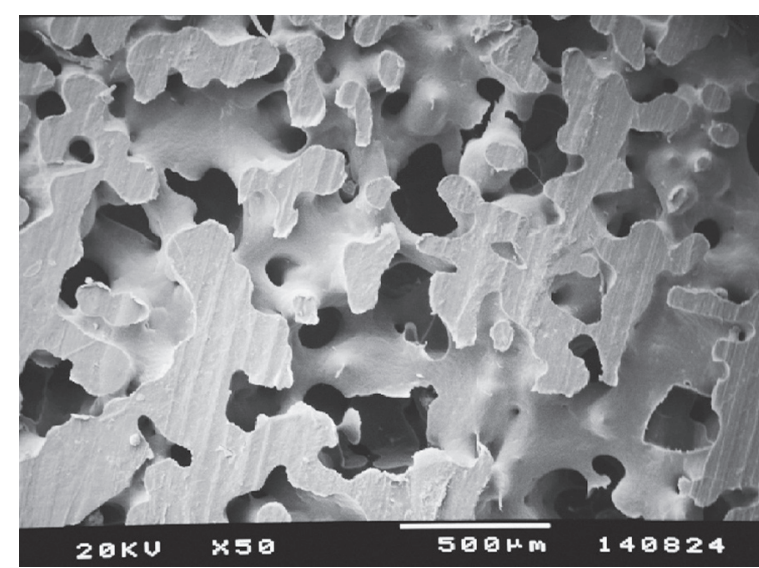

(f)

Figura 1. MEV das amostras porosas de PEUAPM obtidas com a aplicação de pressão de: a) 0,5 ton; b) 1,0 ton; c) 1,5 ton; d) 2,0 ton; e) 2,5 ton; e f) 3,0 ton.

Tabela 2. Diâmetro médio de poros $(\mu \mathrm{m})$ e porosidade $(\%)$ das amostras obtidas.

\begin{tabular}{ccc}
\hline $\begin{array}{c}\text { Pressão aplicada } \\
\text { (ton) }\end{array}$ & $\begin{array}{c}\text { Diâmetro médio de } \\
\text { poros }(\mu \mathbf{m})\end{array}$ & Porosidade $(\%)$ \\
\hline 0,5 & 49,46 & 39,6 \\
1,0 & 42,47 & 53,0 \\
1,5 & 41,99 & 53,6 \\
2,0 & 39,49 & 50,6 \\
2,5 & 46,81 & 40,9 \\
3,0 & 43,52 & 39,1 \\
\hline
\end{tabular}

tida com a aplicação de pressão de 3,0 ton pode ser explicada pela maior compactação das partículas de PEUAPM e $\mathrm{NaCl}$, a qual pode ter dificultado a lixiviação das partículas do sal. Contudo, o comportamento inverso que seria esperado pela amostra obtida com a aplicação da menor pressão de compactação $(0,5$ ton) não foi observada, porém esta amostra apresentou o maior diâmetro médio de poros.

O comportamento do volume cumulativo de poros foi dividido em dois grupos, Figura 2. O primeiro consiste das amostras obtidas com a aplicação de pressão de 0,$5 ; 2,5$ e 3,0 ton, 


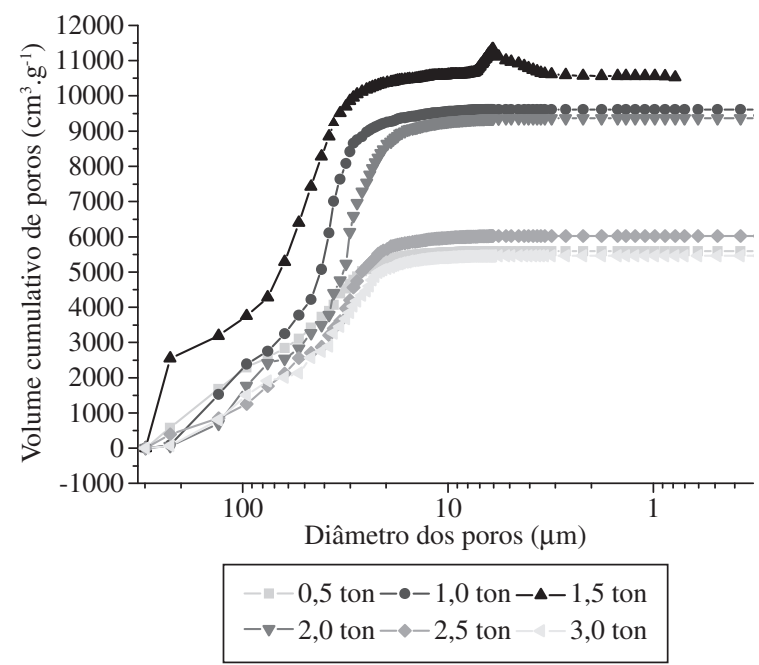

Figura 2. Volume cumulativo de poros em função do diâmetro de poros das amostras porosas obtidas utilizando-se diferentes pressões de compactação.

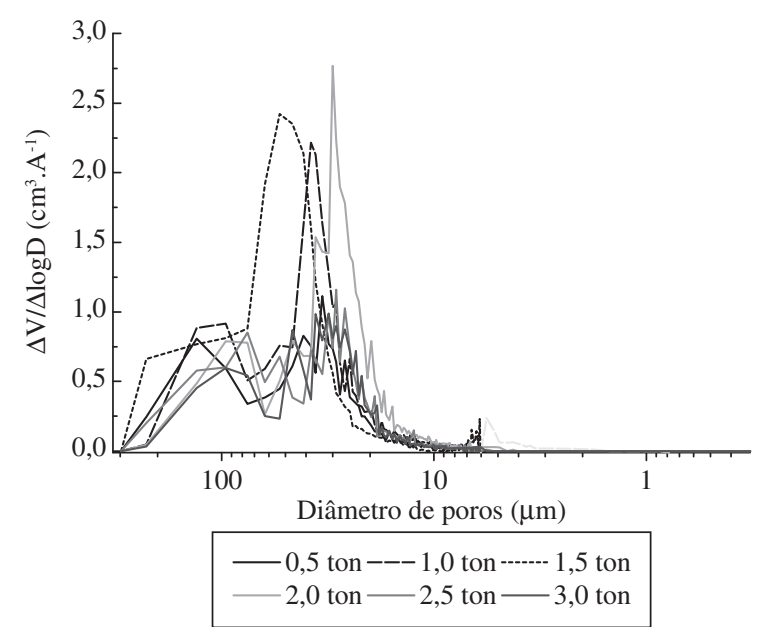

Figura 3. Distribuição diferencial do tamanho de poros das amostras obtidas utilizando-se diferentes pressões de compactação.

as quais exibiram o menor volume de poros. Diferentemente, o segundo grupo é formado pelas amostras que apresentaram o maior volume de poros, aquelas obtidas com a aplicação de pressão de 1,0;1,5 e 2,0 ton. A diferença de volume entre os dois grupos foi cerca de $400 \mathrm{~cm}^{3} \cdot \mathrm{g}^{-1}$. O aumento progressivo da pressão de compactação não influenciou diretamente o volume de poros das amostras. De maneira geral, a amostra obtida aplicando-se a pressão de 1,5 ton apresentou o maior volume de poros, enquanto que a obtida com a aplicação de 3,0 ton apresentou o menor volume de poros. O comportamento apresentado por esta última pode novamente ser explicado pela elevada compactação das partículas dos componentes, dificultando a lixiviação das partículas do sal.

A distribuição de tamanhos de poros foi semelhante para todas as amostras, apresentando duas famílias de poros (distribuição bimodal) com larga distribuição de tamanhos de poros, com diâmetros médios em torno de 30 e $100 \mu \mathrm{m}$, Figura 3. Somente a amostra obtida com a aplicação de pressão 1,5 ton apresentou uma família de poros com diâmetro inferior a $10 \mu \mathrm{m}$.

\section{Conclusões}

A combinação de lixiviação de partículas de sal, utilizando-se $20 \%$ em massa de $\mathrm{NaCl}$ com larga distribuição granulométrica, e moldagem por compressão com a aplicação de diferentes pressões de compactação mostrou-se eficiente na obtenção de suportes porosos de PEUAPM. As amostras porosas apresentaram porosidade interconectada com diâmetros médios de poros próximos a $50 \mu \mathrm{m}$ e porosidade superior a $50 \%$, podendo, dessa forma, serem classificadas adequadas para a utilização como biomaterial poroso.

\section{Agradecimentos}

Os autores agradecem à FAPESP (Processo nº 06/60436-3).

\section{Referências Bibliográficas}

1. "Biomateriales de naturaleza inorgânica: metales, aleaciones y cerâmicas". Disponível em: <www.raf.es/pdf/ acadcorresp_recepcion>. Acesso em: 4 jan. 2005

2. Boschi, A. O. - "O que é necessário para que um material possa ser considerado um biomaterial?", in: Congresso Anual da Associação Brasileira de Metalurgia, p.43, São Paulo - SP (1996).

3. Hench, L. L. - Biomaterials, 19, p.1419, (1998).

4. Cao, W. \& Hench, L. L. - Ceram. Int., 22, p.493, (1996).

5. Hench, L. L. - "Biomaterials, artificial organs and tissue engineering", CRC Press, (2005).

6. Barbanti, S. H. - Polimeros: Cienc Tecnol, 15, p.13, (2005).

7. Otsuki, B.; Takemoto, M.; Fujibayashi, S.; Neo, M.; Kokubo, T. \& Nakamura, T. - Biomaterials, 27, p.5892, (2006).

8. Jones, A. C.; Arns, C. H.; Sheppard, A. P.; Hutmacher, D. W.; Milthorpe, B. K. \& Knackstedt, M. A. - Biomaterials, 28, p. 2491, (2007).

9. Saiz, E.; Gremillard, L.; Menendez, G.; Miranda, P.; Gryn, K. \& Tomsia, A. P. - Mater. Sci. and Eng. C, 27, p.546, (2007).

10. Itala, A. I., Ylanen H. O., Ekholm C., Karlsson K. H., Aro H. T. - J. Biomed. Mater. Res., 58, p.679, (2001).

11. Park, J. B. \& Lakes, R. S. - "Biomaterials an introduction", Plenum Press, New York, (1992).

12. Oréfice, R. L. - "Biomateriais: fundamentos e aplicações", Cultura Médica, Rio de Janeiro, (2006).

13. Wu, L. - Biomaterials, 27, p.185, (2006).

14. Coutinho, F. M. B.; Mello, I. L. \& Santa Maria, L. C. - Polimeros: Cienc Tecnol, 1, p.1, (2003).

15. Reggiani, M. - J. of Molecular Structure, 785, p.98, (2006).

16. Turell, M. B. - Biomaterials, 25, p.3389, (2004).

17. Kurtz, S. M. - "The UHMWPE Handbook: Ultra-high Molecular Weith Polyethylene in Total Joint Replacement", Elsevier Academic Press, New York, (2004).

Enviado: $21 / 02 / 08$

Reenviado: $10 / 05 / 08$

Aceito: $21 / 05 / 08$ 